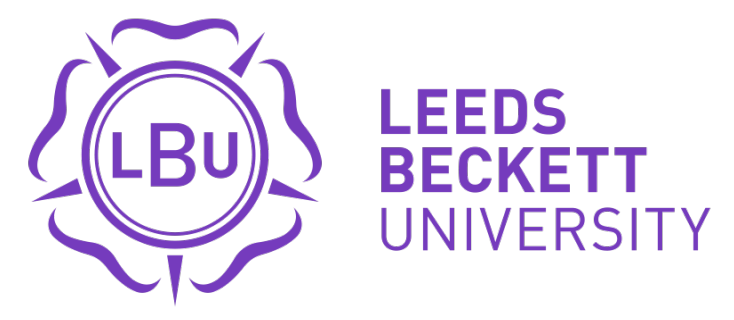

\title{
Citation:
}

Lamond, I (2020) Narrating absence: Fan Con events and the commodification of leisure. Journal of Fandom Studies, 8 (1). pp. 33-46. ISSN 2046-6692 DOI: https://doi.org/10.1386/jfs_00008_1

Link to Leeds Beckett Repository record:

https://eprints.leedsbeckett.ac.uk/id/eprint/6204/

Document Version:

Article (Accepted Version)

(C) Lammond, 2020. The definitive, peer reviewed and edited version of this article is published in Journal of Fandom Studies, 8(1), 33-46, 2020, https://doi.org/10.1386/jfs_00008_1

The aim of the Leeds Beckett Repository is to provide open access to our research, as required by funder policies and permitted by publishers and copyright law.

The Leeds Beckett repository holds a wide range of publications, each of which has been checked for copyright and the relevant embargo period has been applied by the Research Services team.

We operate on a standard take-down policy. If you are the author or publisher of an output and you would like it removed from the repository, please contact us and we will investigate on a case-by-case basis.

Each thesis in the repository has been cleared where necessary by the author for third party copyright. If you would like a thesis to be removed from the repository or believe there is an issue with copyright, please contact us on openaccess@leedsbeckett.ac.uk and we will investigate on a case-by-case basis. 


\section{Narrating absence: Fan Con events and the commodification of leisure.}

The stimulus for some of the ideas in this paper began when I went on a trip to New York to mark what could be considered to be a significant birthday. Being a big comic book fan and fascinated by the use of sequential art as a vehicle for storytelling, New York has held a strong place in my imagination. At the time of organising my trip I saw it as little more than a nice break away. However, whilst I was there, it soon became apparent to me that there was an element of pilgrimage to my visit. I had my hair cut in Little Tony's on West $49^{\text {th }}$ Street, in Hell's Kitchen, and thought of Matt Murdock (Daredevil) coming in to listen to the news from the streets. My eyes kept being caught by the water towers on top of buildings, and I thought of Spider-Man swinging by. But most precious of all, to me, was to sit in a window seat in Old Tbilisi Gardens, Greenwich Village, with some Baklava and an Espresso and look out onto the small awning for 177 Bleeker Street. For those not in the know, Flat A at 177 had been the apartment shared by comic book writers Roy Thomas and Gary Friedrich. Within the Marvel Comic Book and Cinematic Universes, it is the supposed location of the Sanctum Sanctorum - this plane's residence of Doctor Strange, Master of the Mystic Arts. Picturing the Sanctum where there was a small awning between a tattoo parlour and a shop selling beer, cigarettes and vaping supplies was rather difficult, even for someone convinced that one day they will be able to break through the wall at Kings Cross Station and catch the train departing for Hogwarts from Platform 93/4.

What the experience of watching life pass by the entrance to 177 Bleeker Street led me to consider was the experience of a presence (The Sanctum Sanctorum of Dr Strange) in my encounter with its absence (the actual observation of the awning and the two shops either side of it). It is my reflections around this theme, within the context of Fan Convention (Fan Con) events, especially those larger-scale cons like that of San Diego ComicCon, that this conceptual paper will explore. To begin, we will consider what constitutes a Fan Con event, from a theoretical perspective anchored in critical event studies (CES); as well as outlining what such a perspective is, this will also encompass recognition of aspects of the history and variety of these events. In doing so, it will be found to be of value to work with both the ideas of absence and presence, derived from principles established by Jacques Lacan, and 
those of space, as conceived by Henri Lefebvre. That section will conclude by suggesting that Fan Con events represent managed evental spaces of absence.

This will be followed by a discussion of the leisure practices through which Fandom engages with Fan Cons. In order to address that topic we will consider the tripartite division of Leisure developed by Rob Stebbins. Adopting that framework enables us to grasp the complexity and nuance of fan-based leisure practices, however, it does not progress an understanding of the discourses through which those practice are articulated. In order to do that we draw on an application of Habermasian theory to communicative relationships within leisure communities, such as that present in the work of Karl Spracklen (2013). Similar to the analysis of Fan Con events, those ideas will be considered within a Lacanian framework around absence and presence. That, in turn, enables us to obtain an understanding of the importance of those concepts to fandom leisure practice, and associated discourses of fandom, as articulated by fans. Finally, those two pathways will be drawn together to argue that Fan Con events combine fan arena for the articulation of narratives around presence and absence and, especially in larger scale variants of those events, opportunities for the commodification and monetization of those leisure narratives.

\section{Conceptualising Fan Con Events}

According to Coppa (2006) and Geraghty (2014) the first fan convention event can be traced back to the World Science Fiction Convention, held in New York in 1939. To state this, however, carries an implicit understanding of what constitutes both a fan and a gathering of such participants that would, ostensibly, lay a minimal foundation for such an event. Etymologically fan, a contraction of fanatic, has its roots in theology; a fanatic being an individual that is possessed, commonly to the point of insanity, by some spiritual and/or divine entity (Renton, 2018). Inquiries that have drawn close parallels between religious behaviour and fandom frequently conceptualise fans as pilgrims (such as Couldry, 2000, Hanna, 2014, and Yamato, 2018), and conventions as sites of pilgrimage (Porter, 2004; Hill, 2017; Herrmann, 2018). Though not universally supported (Cavicchi, 1998; Duffett, 2013), such interpretations would place some forms of fan event, much earlier. Consequently, determining when Fan Cons began is problematic as a starting point for a conceptualisation 
of such events. However, the history of what is considered to be one of the largest events within that arena (San Diego Comic Con), is less difficult to elaborate.

Established by Sheldon Dorf and some close friends in 1970, and hosted in a small venue in San Diego, California, what was initially known as the Golden State Comic-Con and became San Diego Comic-Con (SDCC) drew in around 300 attendees to its first iteration (Elliott, 2018). Though a definitive figure could not be obtained, it has been estimated that more than $135,000^{*}$ attended the four-day event in July 2018 , with more than 200,000 drawn to San Diego as a result of the convention (San Diego Convention Centre, 2018). Whilst SDCC presents a template through which several independent and franchised Fan Cons operate, it does not exhaustively represent the format of what can be drawn into this form of fan engagement. Booth (2016) suggests that "[d]ifferent fan conventions create different fan spaces" (p.39). He suggests cons range in scale from small fan-run events where there are “...no celebrity guests, no photo ops, no autograph sessions, no actor Q\&A's" (Zubernis \& Larsen, 2012), to ones that are significantly larger, such as SDCC, which are; “...general 'fan' cons with scores of media and entertainment guests, a focus on the dealer's room..., and multiple speaker panels running simultaneously (some from fan speakers and others with industry/actor speakers)" (Booth, 2016, p.40). Booth goes on to assert that there are "hundreds of conventions that fit somewhere in-between" (Ibid. p.40) those two extremes of scale and format. But beyond that, Geraghty (2014) also suggests that such events also constitute communal and affective spaces where; "emotional connections between fans and actors and between fans and fans [occurs]... where commodities such as toys, props, and autographs could be bought and sold." (p. 93)

How are we to conceptualise such diversity? It is here that approaching the questions from a perspective of CES can bring us a step closer, albeit a relatively small one. CES argues that seeking a singular narrative that can capture the essence of the 'event' is to adopt a significant error of attribution. An error that indicates more about the attributors frame of

\footnotetext{
* The figure for attendance at the 2015 SDCC is placed much higher on Wikipedia, 167,000, suggesting actual attendance may be higher. However, the reference for that source is a newsfeed and its veracity cannot be confirmed. The source for the figures used in the text are from the San Diego Convention Centre, where the Comic-Con is held.
} 
reference from within the discursive regimes of a community of practice (Wenger, 2000), itself is a reflection of the dominant cultural political economy (Jessop, 2004)) from within which the attribution is being articulated, than the 'event' itself. According to Spracklen \& Lamond (2016), all 'events' are essentially contested; that is, they are only graspable as multiple and interpretable through a recognition that the event is constituted through an abstraction from what are actually complex, fractally connected ${ }^{*}$, interweaving layers. In place of seeking a singular narrative for the 'event' we are tasked to seek a multiplicity of narratives, where discursive regimes of those drawn into it may not, necessarily, cohere.

As a consequence, following Badiou (2008), the 'event' becomes understood as evental. In place of seeking a conceptualisation through an approach that endeavours to essentialise the Fan Con, CES leads us to consider how it may be construed through confronting its multiplicity. In her work on spaces of vintage fashion consumption (The vintage fashionista may also be considered a form of fandom) Pugh (2019) argues that such spaces of consumption can be substantively apprehended through a critical spatial theory grounded in Lefebvre's three-part dialectic (Lefebvre, 1991). Though that approach distinguishes conceived space (conçu), representational space (vécu) and lived space (perçu), Lefebvre suggests that they need to be worked in combination. He does this in Rhythmanalysis (Lefebvre, 2004) where he writes: “...the act of rhythm analysis integrates these...in an ensemble full of meaning" (p.22), one that conflates the spatial and the temporal into what Michel de Certeau refers to as "narrative structures" (de Certeau, 1988 p. 115).

Fan Cons thus, when seen through the lens of CES, become a fuzzy evental landscape within which a multiplicity of narrative structures interlace in ways that can be coherent, concomitant or contested. I use the word fuzzy here to emphasise that such events can never be grasped as a singular essence. Interaction within that evental landscape occurring at what Lacan might describe as the intersection between the Imaginary and the Symbolic (Lacan, 1992 p.14), articulated through the discursive practices of fandom made manifest by, amongst others, the setting/ structure of the con, the commercial agents present and

\footnotetext{
* By 'fractally connected' the intention is to convey an impression that the apparent simplicity of a connection hides its actual complexity, and that there are no points where the connections are not complex interweaving layers.
} 
the fans themselves. Arguably, unlike those in everyday life, Fan Con interactions can never attain an encounter with a Lacanian Real; i.e. as that which is encountered as resolutely present and apart, or - in his words - "that which is always in the same place" (Ibid. p.85), that can never be grasped by a significatory system. Our encounter with the Real is that of desire, understood as a continuous striving to be expressed through an interconnected and self-supporting system of signifiers. However, the operation of such expression cannot be achieved; to do so would separate (castrate) it from the Real (Lacan, 2007), meaning it would withdraw into the relational significatory structures between the Imaginary and the Symbolic (Lacan, 1992).

Fan Con interactions, conversely, emanate from the narratives articulated through that system of interconnected, self-supporting, signifiers that constitute the evolving and adapting narratives towards which the fan is intentionally, in a Husserlian sense (1973), directed. As such they function as a form of desire that draws from the Imaginary and Symbolic to reach out to the Real yet can never attain it. How could such an encounter ever be communicated within a Fan Con discourse? Let us imagine an exhibit within a Comic Con where there is a reconstruction of the Benatar (a space ship used by the Guardians of the Galaxy, in the second Guardians film). On that reconstruction fans can interact with an animatronic Groot (one of the characters from those films). This can only ever occur as a fan experience if a real Benatar and Groot are absent. If present, fandom would depart and the Real would abruptly confront the startled participant; it forms what Stone (, 2018), in his discussion of dark tourism, refers to as an absent-present paradox, though in the case of fandom it could be argued that it is that which is present that is signifying the unattainable absent. This differs from the voids discussed by Huyssen (2003), when discussing the void spaces in the Jewish Museum in Berlin; such spaces force a confrontation with, rather than the ultimate unrealisabilty of, the Real.

When one starts to consider Fan Cons in terms of the absent-present, or the potential possibility of a present-absent, one can see it everywhere, and in the full range of such convention events, as suggested by Booth (2016). In the smaller, simpler, fan and enthusiast-based events, the absent made present is central to the foundations of the evental landscape in which they are occurring. For the Cons, large Q\&A panels are an 
absent-present for the film(s) to be released, or the series not yet on the air. Meeting an actor from a series, or film franchise (for example - Patrick Stewart), is an encounter with that which is absent (in this instance Captain Jean Luc Picard or Professor Charles Xavier, depending on the flavour of the fan's connection). The experience of that encounter is enhanced when the said actor can affectively make that experience of the absent appear less pronounced, maybe by using a few words (such as Patrick Stewart saying Captain Picard's famous phrase - 'Make it so'). Likewise, it is the presence of the cosplayers in the great hall of a Fan Con that suggests the absence of what they are portraying. 'Amazing outfit'; 'You've got the make-up spot on', 'It's like I'm stood right next to Ryuk"'; statements such as these only make sense where interaction is in the Imaginary/ Symbolic order. To assume interaction in the order of the Real would be to confuse these encounters with the child's struggle to understand how there can be so many real Santa's, as they have seen one in every store they have been to. For myself, it was the present in the form of the awning, the beer \& vaping shop, and the tattoo parlour, that meant I encountered the Sanctum Sanctorum as present in its absence, those few years ago, in New York. To conclude this section. We may conceptualise Fan Con events not simply as evental landscapes but ones that seek to manage absence actively, through what they make present. Now let us consider fans.

\section{Conceptualising Fan Engagement at Fan Cons}

In order to approach the conceptualisation of fan engagement with fan conventions I will begin with a foundational assumption, that fan engagement has a strong connection to an individual's leisure practice. Whist it may be true that some fans can extend their connection through an articulation of their fandom through paid employment and, in some cases, a lucrative career, the root connection is to an engagement at the level of a leisure practice. The fan who is a sales assistant in a comic store, the show runner on a cult TV series, or the director of a multi-million-dollar MCU blockbuster movie, does not stop being a fan just because the cheques start rolling into the bank. Consequently, if we are to understand fan engagement we must, at least, have a clearer understanding of what

\footnotetext{
*A 'death spirit' that appears as a central figure in the manga series 'Death Note'
} 
constitutes leisure practice around fandom. One of the most helpful routes, I would argue, into understanding the diversity of leisure practice is that developed by Rob Stebbins. Stebbins breaks leisure down into three dominant, though related, structures, which he refers to as casual, project-based and serious leisure (Stebbins, 2008).

Stebbins began seeking a way to conceptualise leisure practices in the mid-1970s. In his 1977 paper "The amateur: Two sociological definitions" (Stebbins, 1977), he concludes that we must avoid "unidimensional thinking" (p. 601) when considering the relationship between the amateur and the professional. His way through this, at that point, was to offer a theorisation of a relationship that locates the amateur "as [a] member of a professionalamateur-public system" (Ibid), i.e. within a sociological framework that interprets such practices through co-dependant definitions, rather than a singular definition, with the other being its negation. His ideas developed further through later papers. The paper '"Amateur' and 'Hobbyist' as concepts for the study of leisure problems" (Stebbins, 1980) leads him into drawing out a conceptual difference between the amateur and the hobbyist. He ends that work by suggesting:

"...when the seriousness of hobbies and the seriousness and necessity of amateur pursuits begin to outweigh their durable benefits, the participant can withdraw with less cost than can - to make the obvious comparison - the professional. Research on amateurs, however, indicates that, for many of them, this breaking point is remarkably high... Certain durable benefits attract them and foster the work like attitudes of seriousness, obligation, necessity and commitment that ensure that those benefits will accrue at an acceptable rate." (p. 416-417)

From this point, Stebbins began to examine leisure practices under the three dominant frameworks mentioned earlier; presenting their primary characteristics through several papers and books (for example, Stebbins 1982; 1997 and 2005).

Casual leisure refers to short-lived activities from which the participant obtains immediate and intrinsic pleasure. Such pursuits require very little to no specialist knowledge, and as training is neither needed nor required, such activity is, consequently, relatively 
uncomplicated. Project-based leisure tends to be a short-term, though not short-lived, activity that is unlikely to result in an immediate reward. Not all the activities associated with this form of leisure will be pleasurable, but they are likely to build into a one-off or occasional pleasurable outcome. Because of the role played in building towards that outcome, such pursuits are likely to involve some level of creative activities and, consequently, this form of leisure requires access to, or the development of, greater knowledge and skills. Project-based leisure tends, therefore, to be more complex, and require a more sustained commitment, than casual leisure. Serious leisure requires a much more systematic and structured approach to engagement by its participants. The rewards from such leisure practices are sustained and will be drawn out over an extended period - in some cases encompassing a lifetime. Participants accrue a substantial sense of personal fulfilment from their engagement, which supports their sense of self and identity, through such pursuits. Within this form of leisure practice, the participant acquires a considerable skill-set, a specialist knowledge base, and a web of networked relationships that deepen, frame and facilitate the articulation of their leisure activities. Outputs from such engagement will be textured, and nuanced, involving them in complex actions and interactions*.

Stebbins tripartite construction of leisure not only lays out the parameters within which leisure may be understood as a positive practice, in contrast to a construal of it that is merely a negation of activities associated with work time, it also provides us with a rich framework through which to understand fan engagement with Fan Cons. It conceptualises leisure as something that is "...framed in the social-psychological, social, cultural, and historical context in which the activity and experience take place" (Stebbins, 2008 p. 336). I would argue that for the majority of fans, time spent at, preparing and post-event reflecting on their attending a Fan Con, represents an articulation of, at the very least, engagement at a project-based level of engagement, with a high likelihood that many are engaging as part of a serious leisure practice. For high profile and larger fan conventions both the cost and the length of time required, pre-event, to ensure you can gain access to the convention would work as a barrier to participant attendance that was on the basis of

\footnotetext{
* The descriptions of the three frameworks of leisure I have presented here are based on my own reading of the work of Stebbins referenced above.
} 
casual leisure. Booking may require pre-registration of an expression of interest before one is able to progress through to being considered for ticket purchase. Pre-registration alone, may not be sufficient to guarantee that a prospective attendee can acquire a ticket. Additionally, the financial commitment to some cons can be substantial. A full adult ticket for the 2019 SDCC, which will cover the four days and the preview night, is \$276 (sdccblog.com, ND). That, however, excludes attending any of the high-profile panels associated with film series, TV show, or production companies. Participation as a Cosplayer, meeting actors, obtaining an autograph etc. etc., adds further to that expense. There is also the cost of getting to San Diego and accommodation/ subsistence, whilst you are there. Joel Anderson of the website GoBankingRates estimated, conservatively, that a very basic package for most people attending SDCC in 2018, would be in the region of $\$ 2480$ (Anderson, 2018-How-Much-Are-Comic-Con-Tickets?).

Yet, leisure practice is far more than an articulation of an individuated association with an activity. Fandom is a communal leisure practice, with its own language, etiquette, norms and values, that manifest themselves through complex networks of signification and performativity. It is the difficulties around inquiry into the languages or, more accurately, the discourses articulated through fandom that forms the foundation of Cristofari \& Guitton's (2017) discussion of the place aca-fans (people who identify as both academics and fans in their research into fandom) in fan studies research. Debate around emic and etic orientations within ethno-anthropological research has a long history. Cristofari \& Guitton suggest this is less of an issue than it is commonly taken for, arguing that aca-fans act as a node between those two realms. Speaking both languages, they take a position as multilingual interrogators within the field. Whilst insider/ outsider relationships to a research area continue to be a point of much dispute (Roach, 2014) it would appear one that is only ever applied to the social sciences and humanities. Bad research is bad research, not because it is written from an insider or outsider perspective. I have yet to hear Prof. Brian Cox's research being accused of insider bias, despite his clear fandom for particle physics.

Whilst there is a substantial element of materiality around fandom, the purchase of memorabilia; paying to be in an autograph queue; purchasing comics, posters, graphic 
novels; buying a ticket to have a photo-op with your favourite star etc., the role of interpersonal communications between fans, within a fan community, is central to the emergence of the discourses within which its participants articulate their leisure practice (Bernstein, 2012; Herrmann, 2018; Yamato, 2018). To that extent, following Spracklen (2013), it can be argued that fan-based activities follow other forms of leisure in that the essence of their relationality is communicative. Within fandom, communicative relationships are both wide ranging (fans will be able to express their enthusiasm for their genre/ sub-genre in a manner that can be apprehended by a variety of other fans, who may not hold their precise proclivities) whilst also being fine grained (within Star Trek fandom, for example, the differentiation between a Trekkie and a Trekker is not subtle if you adamantly identify as one rather than the other). Whilst there is a good argument that can be made as to how the materiality around the leisure practices of fandom suggests a colonisation of their lifeworld by neo-liberalist and globalised economic forces (Scambler, 2005; Hanna, 2014), the communitas (Turner, 1996) that emerges through their communicative relationships also points to how fandom also constitutes its own public sphere (Morgan, 2006). As with the Cristofari \& Guitton's (2017) discussion of aca-fans, the communicative relationships between fans can construe their leisure practice as multilingual, drawing on the instrumental rationality of the commercialised aspects of their engagement whilst also generating their own communicative rationality. Rather than the colonising impact of instrumental rationality obliterating fandom, the relationship is much more fluid and interpenetrating. As early as 1992 Fiske was to argue that fandom, as a subculture, has both a significant impact on the commercialised material of which it is a fan as well as a generative aspect that constitute it as "a 'shadow economy' that lies outside that of the cultural industries" (Fiske, 1992 p. 30), whilst sharing many of its features. Einwachter (ND) argues that, given the relatively easy access many now have to high specification digital equipment and the combination of global connectivity and the ubiquity of personal digital communications,

"[the] productivity of fandom has acquired a new economic dimension. Fans not only pass on official marketing information to other fans, but they produce and distribute media content, which we can consider innovative." (NP) 
Whilst there are many, I will use just two examples to illustrate this. Snowqueens Icedragon, a pen name, posted elements of an erotic fantasy based on characters within the mythos of the tetralogy that forms The Twilight Saga (by Stephanie Meyer). Originally titled "Master of the Universe" this Fanfiction would be picked up by a publisher and go on to form the independently bestselling Fifty Shades of Grey. In 2014 Billy Hanshaw, a professional illustrator, designer, and a Doctor Who fan, posted on YouTube, a digitally animated opening credits sequence for Peter Capaldi's incarnation as the $13^{\text {th }}$ Doctor. That sequence so impressed the then show runner (Stephen Moffatt) that he requested permission to realise Billy's concept as the basis for the titles sequence for the show's coming season.

However, as well as affectively drawing together a fan community, communicative relationality can also work to fragment it, highlighting points of contestation around what can be construed as legitimate or illegitimate within the mythos of the fan's fictional universe of preference. Discussion through Reddit and sub-reddit accounts; Vlogs on YouTube channels; Patreon accounts; blog posts, etc. and the associated comments of those that reserve their views to responding to the channels they subscribe to, where such forms of fan content are presented, are replete with reference to whether or not $x$ or $y$ can be considered canon.

The idea of canon, much like that of the word 'fan', has theological roots. In Biblical scholarship canonical works are those that are approved by religious leaders. The books of the New Testament, for example, are canonical as they are thought to shape, and be shaped by, the accepted narratives of the Christian tradition. In fandom, canonicity accrues to mediated elements of certain universe building narrative structures where the coherence of either new material, older or side material, is questioned. Similar to the idea of provenance within the realm of antique acquisition or art collection, canon goes beyond simple continuity issues, associated with the complex narratives of something like a film franchise, to become an attribute of axiological significance for fans. To ask if something is canon is to attribute authenticity of a given narrative output, whilst also constituting a laboratory through which theories associated with where a story arc is headed, or the broader narratives that hold a season/ film series arc together, can be tested. Such questioning and testing commonly occurring in the absence of any other substantive material. Canon can 
thus be considered a form of presence through the application of a generative narration of absence. To draw this back to the Lacan's tripartite structure of the Imaginary, Symbolic and Real; canon is concerned with drawing something that is occurrent in the Symbolic order to establish its coherence with an approved Imaginary. In the absence of a connection to the Real, canon seeks to imbue a semblance of the Real on a Symbolic/ Imaginary dyad. As noted earlier, we can interpret fandom's connectivity to Fan Con events through the lens of CES by considering their contested/ multiplicity of place as articulated through an interplay of the absent and the present at Fan Con events. It is the absence of the Real from the narrative that means that the rupture sits between the Imaginary and the Symbolic rather than between that dyad and the Real. It is not a rupture between the Real and the Imaginary that suggests a gap that the Symbolic order seeks to fill, but a tension between a given Symbolic order and the Imaginary. Canon thus becomes one of the core domains within which the leisure practices of fans converge, and can become articulated through, the absent/ present of the convention. To use Lacan's terminology, Jouissance ${ }^{*}$ thus takes the form of seeking cohesion and consistency through reference to canon, as the striving to bridge a rupture of the Symbolic order and the Imaginary as it reaches for, but can never attain, the Real.

So, where have we got to with our exploration of how to conceptualise fan engagement with Fan Con events? Drawing on the structural representation of leisure in the work of Stebbins, it was suggested that we should not view fan engagement as singular, but as multiple. Fan leisure can be viewed as either casual, project-based, or serious, in the sense he outlines. However, given the financial barriers and the necessity for significant planning associated with participation at larger cons, and the skills some will require in articulating their participation whilst at the event, most fans will engage with cons as a project-based or serious leisure practice. In line with Spracklen's further developments around leisure theory we can construe fans as participating in communicative relationships, constituting their own public spheres (Spracklen, 2017) and, I have suggested, articulating themselves through a

\footnotetext{
* A direct translation would be pleasure; ranging from simple enjoyment to ecstasy. In Seminar XX Lacan uses Jouissance to suggest an intense rupture between subjectivity and the Real that reveals a gap in the Symbolic/ Imaginary dyad. The drive to resolve that rupture becomes articulated through the Symbolic order but, in so doing, the connection to the Real is lost (Lacan, 1998).
} 
sort of multilingualism that bridges instrumental and communicative rationality. Central to that multilingualism, within the context of a Fan Con event, is how fans navigate the evental spaces of managed absence at Fan Cons. Those spaces, in conjunction with the convention's materiality, contribute to how fans can, in the absence of anything more substantive, inform, re-set, reinforce or contest consideration of what constitutes accepted canon. In the final section, I'll draw the two themes discussed in this paper more closely together. In doing so I will consider how Fan Cons use the narrating of absence to commodify fan's leisure practices, thereby monetising it, whilst fans use similar narrations to sustain their Fan Con engagement as an attribute of their project-based or serious leisure practice.

\section{In Conclusion: Narrating absence and presence}

Narrating the interplay between absence and presence, I would suggest, is central to understanding how the two themes discussed in this paper intersect. Both the Fan Con and the fan are constructing and co-constructing narratives that facilitate complex and, to repeat an expression I adopted earlier, fractally connected discourses that bridge instrumental and communicative rationalities. Through using a perspective anchored in CES to reflect on the manifestation of the evental and the performativity of space presented by Fan Cons, we were led to conceptualise such 'events' as evental spaces of managed absence. For example, within Fan Cons, especially larger ones like SDCC, such spaces could be identified in (but not limited to):

- Areas for the managed meetings with your favourite personalities from TV/ Film/ the world of comics etc. with opportunities for photographs with them or autographs from them. In such spaces the presence of the character is encountered in their absence through the interpersonal presence of the person that played that character within the film/ TV series etc. This is also the case where the encounter is with a writer, director, composer etc. We may queue to meet Jeff Russo, or Mike Mignola and pay to have photo with one of them, or an autograph, but our encounter is with either the main composer for Star Trek: Discovery or the creator/writer of Hellboy. The intentionality of our experience is with the absent that we encounter as present, through its absences. 
- Dedicated spaces where attendees can participate in cosplay competitions or simply parade in their outfits. Such spaces forming arena where participants performatively articulate the absent character through their embodied presence, as well and the character being made present through its material absence. Additionally, some cosplay and crossplay* performers may be making present an aspect of their identity that is normally absent.

- Opportunities to be part of the audience attending a panel presentation or discussion around some forthcoming TV/ Film/ Comics productions. In these contexts it is the forthcoming season, or film, or comic cross-over arc, or similar, which is present through its absence. Such forums being a primary arena for the promotion and marketing of the absent media they are making present.

- Large, often open, market places where fans can purchase memorabilia, merchandising, graphics, etc. There are so many layers of presence and absence in such a domain. Such as feeding into a fan's need for completion in finding an absent comic (By the way, I'm just missing issue 14 of Steve Gerber's initial run of his Howard the Duck comic); a favourite series variant cover they're missing; or a rare franchise authorised figurine.

All these feed into fan narratives of absence and presence, and presence through absence. For the con and those businesses that they work through, whether small trader or global entertainment corporation, it is the narratives around the presence through absence that create the money-making opportunities. Through Fan Cons, fans can be engaged, and their leisure fandom commodified, so that both presence and absence can be monetised. Through teasing that somewhat quixotic relationship at the heart of the Imaginary and Symbolic order dyad, the evental spaces of managed absence within Fan Cons can be instrumentalised to sustain, monetise and, it could be suggested, manipulate fandom. However, such a position neglects to factor in the way fandom narrates absence and presence, which is central to fan engagement. As we found though our discussion of the leisure practices they associate with fandom, the relationship the corporate management of

\footnotetext{
${ }^{*}$ Crossplay is a form of cosplay where a person dresses as a charter that does not align with the gender they have been ascribed.
} 
absence and the fan's narration of it not uni-directional. Stone's (2018) absent/ present paradox means there is a fluidity around how fans negotiate absence and presence that also imbues them with a degree of power. in addition, we earlier suggested that, through the multilingualism inherent in how fandom manifests its leisure practice, fans can bridge communicative and instrumental rationality and, in so doing, exert further pressure on those seeking to manipulate them. Whilst fans and Fan Con events may rely on narrating the presence of the absent and the absent made present, both feed each other in a symbiotic connection. One that both commodifies, and instrumentalises, leisure, while requiring, for its own sustainability, the communicative action, and relationships, at the heart of fandom.

This paper has focused on a conceptual exploration of the relationship between absence and presence in the Symbolic, Imaginary and Real discernible at Fan Con events and Fan engagement with such events. Within the confines of a relatively short journal paper its best hope is to be a stimulus for further discussion. Future research, however, should also look at how these ideas could be extended beyond those boundaries both within fandom studies as well as other forms of event and leisure activity. By bringing together Lacan's tri-partite framework, the positive formulation of leisure developed by Stebbins, and Spracklen's application of the Habermasian concepts of the public sphere, and communicative and instrumental rationality, we can begin to obtain a deeper insight into how we can enrich our understanding of leisure and of events? Through the combination of these approaches we can gain new perspectives on diverse leisure practices, as varied as those of model railway and figure gaming enthusiast; online gamers and live action role players (AKA: LARPing); DIYers and crafters. A consideration of the absent/ present and the present/ absent affording us opportunities to ask new questions of leisure and the events associated with them, as well as new ways of approaching familiar questions within the fields of fan, leisure and event studies. 


\section{References}

Anderson, J. (2018) Comic-Con 2018: How much are Comic-Con tickets? Going to Comic-Con could set you back a couple thousand dollar. Online at: $<<w w w . g o b a n k i n g r a t e s . c o m ~>>$ Accessed: $18^{\text {th }}$ April 2019.

Badiou, A. (2008) Conditions. Trans. S. Corcoran. London: Continuum International Publishing.

Bernstein, O. (2012) Comic book fans' recommendations ceremony: A look at the interpersonal communication patterns of a unique readers/speakers community. Participations; Journal of Audience \& Reception Studies. 9(2), 74-96

Booth, P. (2016) Crossing Fandom: SuperWhoLock and the Contemporary Fan Audience. London: Palgrave Macmillan.

Cavicchi, D. (1998) Tramps Like Us: Music \& Meaning Among Springsteen Fans. New York: Oxford University Press.

de Certeau, M (1988) The Practice of Everyday Life. Berkley: University of California Press. Coppa, F. (2006) Brief history of media fandom. In K. Hellekson \& K. Busse (Eds.) Fan Fiction and Fan Communities in the Age of the Internet. Pp.41-61. Jefferson: McFarland Press.

Couldry, N. (2000) The Place of Media Power: Pilgrims and Witnesses of the Media Age. London: Routledge.

Cristofari, C. \& Guitton, M.J. (2017) Aca-fans and fan communities: An operational framework. Journal of Consumer Culture. 17(3), 713-731

Duffett, M. (2013) Understanding Fandom: An Introduction to the Study of Media Fan Culture. London: Bloomsbury Academic.

Einwachter, S.G. (ND) Fantastic fan marketing - Fantasy fan online-communities and conventions as markets of cultural goods. Online at $<<$ s3.amazonaws.com/academia.edu >> Accessed: 17th April 2019.

Elliott, M.A. (2018) The globalization of comic-con and the sacralization of popular culture. In A Beniwal; R. Jain; and K. Spracklen (Eds.) Global Leisure and the Struggle for a Better World. p.p. 221-242. Cham: Springer International Publishing.

Fiske, J. (1992) The cultural economy of fandom. In L.A. Lewis (Ed.) The Adoring Audience: Fan Culture and Popular Media. p.p. 30-49. New York: Routledge. 
Geraghty, L. (2014) Cult Collectors: Nostalgia, Fandom and Collecting Popular Culture. Abingdon: Routledge.

Hanna, E.M. (2014) Making Fandom Work: Industry Space and Structures of Power at the San Diego Comic-Con. Unpublished PhD thesis. Online at $<<$ https://deepblue.lib.uich.edu > Accessed: $17^{\text {th }}$ April 2019.

Herrmann, A.F. (2018) Communication and ritual at the comic book shop: The convergence of organizational and popular cultures. Journal of Organizational Ethnography. 7(3), 285301.

Hill, N. (2017) Embodying Cosplay: Fandom Communities in the USA. Unpublished PhD thesis. Online at: $<$ https://scholarworks.gsu.edu $\gg$ Accessed: $17^{\text {th }}$ April 2019.

Husserl, E. (1973) Cartesian Meditations: An Introduction to Phenomenology. Trans. D

Cairns. The Hague: Springer Science+Business Media Dordrecht.

Huyssen, A. (2003) Present Pasts: Urban Palimpsests and the Politics of Memory. Stanford:

Stanford University Press.

Jessop, B. (2004) Critical semiotic analysis and cultural political economy. Critical Discourse Studies. 1(2), 159-174.

Lacan, J. (1992) The Ethics of Psychoanalysis. The Seminar of Jacques Lacan: Book VII. Trans. D. Porter. London, Routledge.

Lacan, J. (1998) On Feminine Sexuality, the Limits of Love and Knowledge, $1972-1973$. The Seminar of Jacques Lacan: Book XX. Trans. B. Fink. New York: W.W. Norton \& Company Lacan, J. (2007) Ecrit. Trans. B. Fink. New York: W.W. Norton \& Company. Lefebvre, H. (1991) The Production of Space. Trans. D. Nicholson-Smith. Oxford: Blackwell Publishers Ltd.

Lefebvre, H. (2004) Rhythmanalysis: Space, Time and Everyday Life. Trans: S. Elden \& G. Moore. London: Continuum.

Morgan, D. (2006) The crisis of masculinity. In K. Davis; M. Evans; \& J. Lorber (Eds.) The Sage Handbook of Gender and Women's Studies. p.p. 109-123. London: Sage.

Porter, J.E. (2004) Pilgrimage and the IDIC ethic: Exploring star trek convention attendance as pilgrimage. In E. Badone \& S.R. Rosem (Eds.) Intersecting Journeys: The Anthropology of Pilgrimage and Tourism. pp. 160-179. Champaign: University of Illinois Press.

Pugh, E. (2019) Unpublished PhD thesis. Awaiting full details from author. 
Renton, J. (2018) The figure of the fanatic: A rebel against Christian sovereignty. Ethnic and Racial Studies. 41(12), 2161-2178.

Roach, C.M. (2014) ,Going Native': Aca-fandom and deep participant observation in popular romance studies. Mosaic: A Journal for the Interdisciplinary Study of Literature. 47(2), 3349.

San Diego Convention Centre (2018) San Diego Comic-Con 2018. Online at: << https://visitsandiego.com $>$ Accessed: $18^{\text {th }}$ April 2019.

Scambler, G. (2005) Sport and Society: History, Power and Culture. Maidenhead: Open University Press.

sdccblog.com (ND) San Diego Comic-Con - Frequently asked questions. Online at: $<<$ https://sdccblog.com $\gg$ Accessed: $18^{\text {th }}$ April 2019.

Spracklen, K. (2013) Leisure at the end of modernity: Jurgen Habermas on the purpose of leisure. In T. Blackshaw (Ed.) Routledge Handbook of Leisure Studies. p.p. 141-149. Abingdon, Routledge.

Spracklen, K. (2017) Leisure, Instrumentality and Communicative Action. In K. Spracklen; B. Lashua; E. Sharpe; \& S. Swain (Eds.) The Palgrave Handbook of Leisure Theory. London: Palgrave Macmillan.

Spracklen, K. \& Lamond, I.R. (2016) Critical Event Studies. Abingdon, Routledge.

Stebbins, R.A. (1977) The amateur: Two sociological definitions. Pacific Sociological Review. 20(4), 582-606.

Stebbins, R.A. (1980) 'Amateur' and 'hobbyist' as concepts for the study of leisure problems. Social Problems. 27(4), 413-417.

Stebbins, R.A. (1982) Serious leisure: A conceptual statement. Pacific Sociological Review. 25(2) 251-272.

Stebbins, R.A. (1997) Casual leisure: A conceptual statement. L:eisure Studies. 16(1), 17-25.

Stebbins, R.A. (2005) Project-based leisure: Theoretical neglect of a common use of free time. Leisure Studies. 24(1), 1-11.

Stebbins, R.A. (2008) Right leisure: Serious, casual, or project-based? NeuroRehabilitation. 23(4), 335-341.

Stone, P. (2018) Dark tourism in an age of 'spectacular death'. In P.R. Stone; T. Seaton; L. White; R. Hartmann \& R. Sharpley (Eds) The Palgrave Handbook of Dark Tourism Studies. pp. 189-210. London: Palgrave Macmillan. 
Turner, V. (1996) The Ritual Process: Structure and Anti-Structure. Abingdon: Routledge.

Wenger, E. (2000) Communities of Practice: Learning, Meaning, and Identity. Cambridge: Cambridge University Press.

Yamato, E. (2018) Constructions of discursive fandom and structural fandom through anime comics and game fan conventions in Malaysia. European Journal of Cultural Studies. 21(4), 469-485.

Zubernis, L. \& Larsen, K. (2012) Fandom at the Crossroads: Celebration, Shame and Fan/ Producer Relationships. Newcastle upon Tyne: Cambridge Scholars Publishing. 